\title{
$=\mathrm{T} R A M A=$
}

\section{FELICIDADE CLANDESTINA NA FANFIC: UMA PROPOSTA DE ABORDAGEM DO TEXTO LITERÁRIO NO ENSINO FUNDAMENTAL ॥}

\author{
GREICE APARECIDA FACIOLI DE BITENCOURT (PROFLETRAS - UEM/UFRN)1 \\ http://orcid.org/0000-0003-2579-3564
}

\author{
SOLANGE APARECIDA BOREGGIO (PROFLETRAS - UEM/UFRN)² \\ http://orcid.org/0000-0001-8305-8934
}

MARGARIDA DA SILVEIRA CORSI (UEM) ${ }^{3}$

http://orcid.org/0000-0002-5216-8660

\begin{abstract}
RESUMO: Considerando que o trabalho com o texto literário em sala de aula continua sendo um dos grandes desafios do professor de Língua Portuguesa e a escassez de propostas de abordagem capazes de reunir práticas pedagógicas e eventos sociais que envolvam a interação entre o leitor, texto literário e autor, o presente trabalho apresenta uma proposta de abordagem do conto Felicidade Clandestina, de Clarice Lispector, voltada para alunos de oitavo e nono ano do ensino fundamental. Este trabalho objetiva promover o letramento literário e a instrumentalização do leitor. Para tanto, idealizamos uma abordagem a ser aplicada em formato de oficina, dividida a partir das etapas descritas por Micheletti (2000) e revistas por CORSI (2015), aliadas aos pilares do dialogismo bakhtiniano (BAKHTIN, 1997): conteúdo temático, estrutura composicional e estilo, partindo do contexto de produção no qual o texto encontra-se inserido. A partir desta visão, esta oficina apresenta as seguintes etapas: motivação/sensibilização, antecipação, leitura/análise e interpretação. Espera-se com isso, desenvolver a criticidade do aluno/leitor e ampliar a sua compreensão por meio da produção de uma fanfiction, gênero que promove a criatividade do leitor através da reescrita e corresponde aos interesses do público alvo a quem este trabalho se destina.
\end{abstract}

PALAVRAS-CHAVE: Formação do leitor. Leitura literária. Gêneros. Conto. Fanfiction.

ABSTRACT: Considering that working with the literary text in the classroom remains one of the great challenges of the Portuguese Language teacher and the scarcity of approach proposals capable of to compile pedagogical practices and social events that involve the interaction between the reader, literary text and author, the present work aims to present a proposal of approach of the tale Felicidade Clandestina, by Clarice Lispector, aimed at the 8th and the 9th grade of elementary school, in order to promote literary literacy and instrumentalization of the reader. For this, we idealized an approach to be applied in a workshop format, divided from the steps described by Micheletti (2000) and revised by CORSI (2015), allied to the pillars of Bakhtinian dialogism (BAKHTIN, 1997): thematic content, compositional structure and style, starting from the production context in which the text is inserted. Based on this vision, this workshop presents the following steps: motivation / awareness, anticipation, reading / analysis and interpretation. It is hoped with this, develop the criticality of the student/reader and broaden their understanding through the production of a fanfiction, Genre that promotes the reader's creativity through rewriting and corresponds corresponds to the interests of the target audience to whom this work is intended.

KEYWORDS: Reader training. Literary reading. Genres. Tale. Fanfiction.

\footnotetext{
${ }^{1}$ Mestranda do ProfLetras - Universidade Estadual de Maringá/Universidade Federal do Rio Grande do Norte. E-mail: greice.facioli@escola.pr.gov.br

${ }_{2}$ Mestranda do ProfLetras - Universidade Estadual de Maringá/ Universidade Federal do Rio Grande do

Norte. E-mail: solangeboreggio@bol.com.br

${ }^{3}$ Professora doutora. Universidade Estadual de Maringá. E-mail: margaridacorsi33@hotmail.com

Revista Trama | Volume 16 | Número 39 | Ano 2020 | pp. 91-103 | e-ISSN 1981-4674
} 


\section{$=$ TRAMA $=$}

\section{INTRODUÇÃO}

Este trabalho apresenta uma proposta para abordagem do conto Felicidade Clandestina, de Clarice Lispector, a partir de teorias que defendem a instrumentalização do leitor como forma formar o leitor crítico. Aliada a isso, a presente proposta também está ancorada nos pressupostos teóricos do dialogismo bakhtiniano (2003) e da leitura subjetiva (JOUVE, 2013).

A partir das reflexões e de várias leituras realizadas durante a disciplina Literatura e Ensino (Mestrado Profissional em Letras - UEM/UFRN) constatou-se que a literatura tem um papel primordial na construção da identidade do sujeito/leitor, pois através das experiências de outros, no caso os personagens ficcionais criados pelos autores literários, é possível compreender melhor a nossa própria vivência. Campagnon (2009) entende a literatura como um exercício de reflexão e experiência de escrita, capaz de refletir o conhecimento do homem e do mundo. O autor salienta que o homem aprende por intermédio da literatura entendida como ficção, já que esta lhe oferece uma representação, imitação, de sua própria realidade, deleitando-o e instruindo-o ao mesmo tempo.

A partir desse poder atribuído ao texto literário por Campagnon, compreendemos a necessidade de se pensar em uma proposta de abordagem do texto literário capaz de promover no aluno o reconhecimento de si mesmo nas experiências de personagens fictícios. Para tanto, foi necessário elaborar um trabalho que conseguisse ultrapassar o limiar de aspectos estruturais do texto, haja vista a infinidade de materiais didáticos voltados para o ensino do texto literário ancorados unicamente na análise linguística, excluindo a riqueza da materialidade literária.

Nesse trabalho apresentamos uma proposta de abordagem com ações que estimulem o letramento literário junto aos alunos de $8^{\circ}$ e $9^{\circ}$ anos do Ensino Fundamental. A partir do qual, pretende-se oferecer ao professor alternativas para o tratamento do texto literário dentro de um contexto de didatização conto, sem que isso sacrifique as características originais do gênero. Além disso, também objetiva-se promover a leitura e a análise de um tema que parece ir ao encontro do interesse dos alunos a quem esta proposta se destina, já que nossas experiências como professoras da rede pública de ensino nos mostram o quanto os adolescentes estão em busca de satisfação pessoal e felicidade.

Nesse sentido, a divisão da presente proposta em etapas de leitura tem o objetivo de possibilitar a esse aluno/leitor posicionar-se criticamente diante do texto escolhido, reconhecendo o projeto de dizer da autora. Ao final da proposta, objetiva-se promover uma efetiva interpretação do texto lido, por meio de uma produção textual na qual o aluno apropriese de características discursivas e linguísticas do gênero em uma situação real de comunicação. Esta proposta justifica-se pelo fato de que o trabalho com o texto literário em sala de aula continua sendo um dos grandes desafios do professor de Língua Portuguesa. Muitos são os estudos desenvolvidos nessa área, mas poucos parecem ser capazes de reunir práticas pedagógicas e eventos sociais que envolvam a interação entre leitor, texto literário e autor, promovendo efetivamente o letramento literário.

O contexto das salas de aula é muito heterogêneo, necessitando de investigações mais aprofundadas para a elaboração de planos de ensino que promovam efetivamente o letramento literário, a partir de práticas sociais que atendam ao contexto no qual estão inseridos. Nesse sentido, faz-se necessário também que, como professores, estejamos sempre dispostos a buscar e pesquisar novas ideias e, principalmente, desenvolver projetos a partir de nossas próprias pesquisas, capazes de contribuir de forma mais efetiva para as reais necessidades dos nossos alunos. 


\section{$=$ TRAMA $=$}

Nesse sentido, não é possível negar que o momento histórico no qual a escola encontrase situada é um momento de interação. Todas as tecnologias desenvolvidas pela humanidade ao longo dos anos chegaram até a escola. Não de forma material, haja vista a dura realidade das escolas brasileiras que sofrem com uma infraestrutura deficitária e obsoleta. Entretanto, não se pode negar que, de forma ideológica, essa tecnologia tem chegado à maioria das escolas brasileiras. Por mais pobre que seja o contexto social no qual a escola encontra-se inserida, os sujeitos participantes desse espaço estão, de alguma forma, conectados aos meios tecnológicos, que orientam e direcionam a vida na sociedade do século XXI.

Portanto, em nossa investigação do contexto no qual nossos alunos estão inseridos, faz-se necessário considerar que eles estão conectados a vários meios tecnológicos e que essa conexão fez mudar também a relação dos leitores com os textos produzidos. Chartier (2007), em seu texto "As revoluções da leitura no ocidente", deixa claras as novas configurações que a era dos textos eletrônicos estabelece entre texto e leitor, afirmando que os leitores desse novo momento tem a possibilidade de tornarem-se coautores dos textos produzidos devido, principalmente, à maleabilidade desses escritos e dos meios nos quais são divulgados.

Entretanto, toda essa interação e evolução tecnológica não parece dar conta de questões ainda muito aflitivas do professor de Língua Portuguesa. Ainda encontramos alunos que pouco sabem ler. Mesmo conectados às redes sociais, vorazmente atualizadas e aos jogos eletrônicos tão repletos de múltiplas linguagens (sons, imagens, cores, luzes, movimentos), muitos ainda situam-se no nível da decodificação.

Dentre essas questões aflitivas que não abandonam o professor, podemos citar as que mais nos inquietaram para a realização desse trabalho: Como trabalhar o texto literário no ensino fundamental II de forma a promover efetivamente o letramento literário? Como despertar o gosto pelo texto literário em meio a esse contexto tecnológico? Como trabalhar a produção textual nesse mesmo contexto? A partir dessas questões tão desafiadoras, elaboramos uma proposta de abordagem no formato de oficina de literatura que culmina com a produção e a socialização de textos produzidos pelos alunos.

A metodologia para a abordagem do conto literário Felicidade Clandestina, de Clarice Lispector, está direcionada aos alunos do $9^{\circ}$ ano do Ensino Fundamental. A escolha do $9^{\circ}$ ano se dá devido ao fato de ser esta a última etapa do ensino fundamental, ou seja, a fase em que, teoricamente, os alunos já tiveram contato com diversos gêneros discursivos e já estudaram e produziram textos com os diferentes modos de organização do discurso (narração, exposição, argumentação, injunção, descrição). A escolha do gênero conto se deu pelo fato de ser um gênero já conhecido dos alunos, porém o seu contexto de produção é pouco explorado pelos materiais didáticos disponíveis ao professor.

Um dos propósitos da escolha da autora Clarice Lispector está ligado à ideia de que a subjetividade de suas obras é pouco explorada no Ensino Fundamental II, porque acredita-se que nessa fase o aluno não conseguiria compreender a introspecção de seus personagens. A grande questão encontra-se na maneira de apresentar aos alunos os textos por ela escritos. $O$ mais importante, contudo, nessa primeira etapa do trabalho com autores consagrados pelo cânone, é o contato com textos de inegável valor literário. É importante lembrar que estamos falando de um processo: a formação do leitor. Nesse sentido, Cosson (2009, p. 35) afirma que:

A diversidade é fundamental quando se compreende que o leitor não nasce feito ou que o simples fato de saber ler não transforma o indivíduo em leitor maduro. Ao contrário, crescemos como leitores quando somos desafiados por leituras progressivamente mais complexas. Portanto, é papel do professor partir daquilo que o aluno já conhece para aquilo que ele desconhece, a fim de se proporcionar o crescimento do leitor por meio da ampliação de seus horizontes de leitura. 


\section{$=$ TRAMA $=$}

Nesse intuito de promover o letramento literário, elaboramos uma proposta de abordagem do texto literário que contempla as etapas descritas por Micheletti (2000) e revistas por Corsi (2015). Além disso, na busca de desenvolver a criticidade do aluno/leitor, procuramos elaborar a referida proposta de forma a contemplar os pilares do dialogismo bakhtiniano: conteúdo temático, estrutura composicional e estilo, partindo do contexto de produção no qual o texto encontra-se inserido. Com o objetivo de promover a interpretação, consideramos o conceito de produção de fanfictions para a promoção do letramento literário, defendido por Candido (2018).

\section{GÊNEROS DISCURSIVOS E TEXTO LITERÁRIO - PERSPECTIVAS DE LEITURA}

O trabalho com a literatura deve ocupar um lugar central no currículo de Língua Portuguesa, já que segundo Cândido (2004) a literatura tem um caráter formativo, devido ao seu potencial humanizador, isto é, possibilita ao leitor o conhecimento e o autoconhecimento, permitindo a expressão, a aproximação e a discussão de diferentes imaginários valores, visões de mundo, comportamentos, impasses e utopias. É possível dizer, portanto, que a literatura reclama seu espaço na escola.

Cândido (2004) ainda afirma que o texto literário é um todo organizado com estrutura própria que constrói significados e que deve ser decifrado pelo leitor/receptor. É na compreensão dessa organização que são elaborados os sentidos vinculados pelo texto literário, produzindo assim, uma sensação de prazer. Pelo exercício de compreensão por parte do leitor, a literatura possibilita a superação do caos, na medida em que se constitui em uma forma de ordem, um modo de ordenamento. "A organização da palavra comunica-se ao nosso espírito e o leva, primeiro, a se organizar; em seguida, a organizar o mundo." (CANDIDO, 2004, p. 177).

Em consonância a esse aspecto, a literatura também apresenta-se como uma forma de produção de conhecimento e de manifestação de emoções e de visões de mundo. A partir disso, é possível entender o texto literário como um veículo de valores axiológicos, conforme a perspectiva bakhtiniana (BAKHTIN, 2003), ou seja, expressa valores e concepções éticoculturais de quem o produz e do meio em que é produzido. Nesse sentido, o enunciado está, pois, relacionado ao tempo e ao espaço de produção, uma vez que o sujeito enunciador fala a partir do lugar social que ocupa associado ao seu contexto histórico. Na construção desse enunciado, torna-se evidente o seu caráter dialógico denunciado pelo enunciador, quando este demonstra estar ou não estar em consonância com esse contexto, tendo em vista que traz em si sempre um viés responsivo, na medida em que dialoga com enunciados anteriores, ao mesmo tempo em que já projeta a réplica de enunciados futuros.

O caráter dialógico do enunciado não se restringe às relações estabelecidas somente pelo enunciador com enunciados anteriores e posteriores, mas também no momento da leitura. Bakhtin (1997) preconiza que o enunciado não se realiza sozinho, porque não consegue manter as trocas discursivas entre os interlocutores. O enunciado para manter-se dentro do processo dialógico implica a compreensão por parte do interlocutor, portanto sugere uma outra ação, denominada enunciação. Tal processo segundo Brait e Melo (2005), define-se como a presença do sujeito leitor no ato discursivo, uma vez que este também leva consigo para a leitura o seu próprio eu, carregado de experiências sócio-históricas, capazes de promover comunicações com outras enunciações. Essas comunicações formam uma cadeia, na qual os enunciados funcionam como os elos de ligação.

Numa perspectiva de organização curricular, é possível conceber a leitura como uma ação interativa e ancorar o trabalho com o texto literário em sala de aula a partir das contribuições que Bakhtin (1997) elaborou sobre a linguagem e seu caráter dialógico, uma vez 


\section{$=$ TRAMA $=$}

que a compreensão para este autor, conforme já foi dito, trata-se de um processo que envolve o sujeito e as experiências sócio-históricas e culturais que o constitui.

Essas experiências sócio-históricas estão ligadas às implicações da leitura subjetiva que Jouve (2013) preconiza como aspecto positivo da relação entre texto e leitor. Para o referido autor, "cada um projeta um pouco de si na sua leitura, por isso, a relação com a obra não significa somente sair de si, mas também retornar a si. A leitura de um texto também é sempre leitura do sujeito por ele mesmo" (JOUVE, 2013, p.53). Nessa perspectiva, o autor defende que considerar a dimensão subjetiva da leitura no plano pedagógico, pode fazer com que o aluno adquira o gosto pela literatura, uma vez que é mais fácil compreender os saberes sobre o mundo partindo dos saberes sobre si mesmo e reconhecendo suas experiências históricas e sociais naquilo que lê.

O reconhecimento de si mesmo no texto requer do professor um trabalho que leve em consideração aspectos ligados a fatores extratextuais. Nesse sentido, para Bakhtin (1997), a leitura em uma perspectiva interacionista diferentemente de como é concebida pelo objetivismo abstrato e pelo subjetivismo idealista, não se pauta em uma investigação na qual toma como base o estudo isolado da oração. O autor defende que todo enunciado é produzido a partir de um contexto de produção e, dessa forma, o fato de não considerar o contexto apaga algumas marcas que caracterizam

[...] os indícios que revelariam seu caráter de dirigir-se a alguém, a influência da resposta pressuposta, a ressonância dialógica que remete aos enunciados anteriores do outro, as marcas atenuadas da alternância dos sujeitos falantes que sulcaram o enunciado por dentro. Tudo isso, sendo alheio à natureza da oração como unidade da língua, perde-se e apaga-se. Esses fenômenos se relacionam com o todo do enunciado e deixam de existir desde que esse todo é perdido de vista (BAKHTIN, 1997 p. 326).

O autor em questão reforça a importância de se considerar o contexto para gerar significado, uma vez que o cruzamento das compreensões dos participantes das trocas dialógicas podem promover enunciações concretas, ou seja, estados de compressão do texto. Essa concepção Bakhtiniana vai ao encontro do que defende Zilberman (2003) quanto à importância do trabalho com o texto literário na escola, já que, segundo a autora, tanto a escola quanto a literatura estão voltadas para a formação do indivíduo e que esta "sintetiza, por meio dos recursos da ficção, uma realidade, que tem amplos pontos de contato com o que o leitor vive cotidianamente". (ZILBERMAN, 2003. p. 25). Para Zilberman,

É desta coincidência entre o mundo representado no texto e o contexto do qual participa seu destinatário que emerge a relação entre a obra e o leitor. Pois, quanto mais este demanda uma consciência do real e um posicionamento perante o mesmo, tanto é o subsídio que o livro de ficção tem a lhe oferecer (...) (ZILBERMAN, 2003, p. 27).

Ainda nesse sentido, Micheletti (2000, p.16) também defende a leitura literária voltada para a ampliação dos sentidos oferecidos pela materialidade do texto, já que, segundo a autora "é dessa leitura que brota a construção do real. Aparentemente preso nas malhas do texto, o leitor salta para a vida e para o real na medida em que a leitura da palavra escrita pode conduzilo a uma interpretação do mundo". Para a referida autora, ler é uma experiência de construção e reconstrução, pois quando o leitor realiza uma leitura profunda, ele entra em contato com as experiências do outro e constrói novas significações, além daquelas que a superfície do texto verbal the possibilitou ler. Quando ele volta à tona desse "mergulho", encontra-se em um outro cenário, podendo ver melhor a si mesmo e o mundo a partir da experiência que o texto the 


\section{$=$ TRAMA $=$}

proporcionou. Entretanto, a autora ressalta que para atingir a essa reconstrução o caminho não é muito fácil. Segundo ela, é um trabalho que precisa ser conduzido pelo professor e dividido em algumas etapas, já que

[...] a leitura ocorre por um complexo mecanismo, em que sucessivas etapas, desde o contato inicial, vão-se interpretando. De início se apreendem os sinais, o código, passando-se a decifrá-lo e, quase simultaneamente, se apreende uma significação de superfície. A tarefa seguinte consiste numa desmontagem para se atingir o significado no interior do próprio discurso, é o momento da análise. Depois vem a interpretação, através de uma re-montagem e, tal como um desenho animado, as palavras vão se juntando e formando o texto, já com um novo sentido para o leitor. É nessa etapa que o diálogo do leitor com o texto se torna mais vivo, pois ele terá ativado todo um conhecimento de mundo e o terá posto em movimento (MICHELETTI, 2002, p.16).

As etapas previstas por Micheletti (2000) podem ser sintetizadas em antecipação, leitura e interpretação. Entretanto, em outro momento, ao discutir alguns dos objetivos educacionais ligados ao ensino da leitura e da literatura elencados por Ana Mariza R. Filipouski (1982), segundo a qual "o objetivo central da escola é o de desenvolver a capacidade de ler e escrever, como forma de autoexpressão e apreensão do mundo" (FILIPOUSKI, p.110, apud MICHELETTI, 2001, p.68), a autora defende que "Para que se consiga esse intento, a escola deverá, basicamente, sensibilizar a criança para a leitura, oferecendo-Ihe diferentes contatos com o texto escrito; e aproximar o texto da realidade social e psicológica do aprendiz, como meio socializador e de refinamento emocional"(MICHELETTI, 2001, p.68).

Nesse sentido, de acordo com CORSI (2015), podemos ampliar as etapas previstas por Micheletti em: sensibilização, antecipação, leitura e interpretação. Corsi (2015) acredita que a proposta de leitura defendida por Micheletti é fundamental para que o processo da leitura do texto literário realmente ocorra de forma satisfatória e eficiente, por isso propõe etapas divididas em: antecipação, decodificação, análise e interpretação, considerando ainda importante a expansão do sentido da temática. Tendo em vistas as referidas leituras, para este trabalho tomaremos como referência uma divisão baseada nas duas propostas, divididas em seis etapas, sendo elas: sensibilização, antecipação, leitura, análise, interpretação e expansão.

\section{OFICINA LITERÁRIA FELICIDADE CLANDESTINA NA FANFIC}

A sensibilização é a primeira etapa da presente oficina literária para abordagem do conto Felicidade Clandestina. Nesse momento, espera-se aproximar o tema felicidade da realidade social e psicológica do aluno, conforme defendido por Micheletti (2001). Para isso, propomos que o professor leve vários emojis, utilizados em redes sociais para expressar humor e felicidade, já impressos e ampliados e distribua-os previamente pelo ambiente escolar.

O professor pode optar por distribuí-los somente pela sala de aula ou, se preferir, levar a outros espaços físicos da escola, como pátio, refeitório, laboratório de informática, entre outros. A intenção é despertar nos alunos a curiosidade e criar expectativa sobre como esses emojis serão utilizados na escola. No momento da aula, o professor pode perguntar aos alunos e solicitar que eles respondam oralmente questões como: a) Em que situações as pessoas costumam usar esses emojis? b)Descreva uma situação vivida por você que poderia ser representada por um desses emojis.

Ainda nesta etapa propomos a utilização de um jogo de tabuleiro intitulado Jogo da Felicidade que também tem por objetivo aproximar o leitor da temática abordada no conto de Clarice Lispector. O jogo foi inspirado em um homônimo encontrado no site https://crescercomemrc.blogspot.com/, e foi adaptado para a realidade proposta. É constituído 


\section{$=$ TRAMA $=$}

por um labirinto que apresenta algumas experiências que, no dia a dia, podem fazer as pessoas felizes ou infelizes, quatro peões, um dado e dez cartas de reflexão compostas por frases e trechos de poemas que abordam o tema felicidade. As cartas são motivacionais e procuram aliar belas imagens aos textos anteriormente descritos, a fim de levar o aluno a refletir sobre como a felicidade está presente em coisas simples da vida. Os jogadores devem jogar o dado e quem tirar o número mais alto começa. O primeiro jogador joga o dado e anda o número de casas indicado pelo dado. Quando parar numa casa vermelha, deve tirar uma carta da casa de reflexão e ler para o grupo.

A próxima etapa é a da antecipação, que se refere ao momento em que o leitor faz o primeiro contato com a obra, levando-se em conta alguns componentes que sejam externos ao texto. Conforme CORSI (2015, p. 34), é “[...] um momento de aproximação do leitor com o livro e sua materialidade física, pressupõe o conhecimento e o reconhecimento de elementos componentes da obra a ser lida como a capa, o título, o número de páginas ou mesmo o formato do livro". Para essa etapa, propomos apresentar ao aluno uma foto da autora Clarice Lispector acompanhada de uma breve biografia. É importante promover um momento de leitura coletiva e fazer perguntas aos alunos: a) Conhecem essa autora? b) Já leram alguma de suas obras? Quais?

Logo em seguida, sugerimos apresentar a capa da $5^{a}$ edição do livro Felicidade Clandestina e explorar alguns aspectos de seus componentes, tais como as ilustrações e as possíveis relações que podem ser estabelecidas entre a ilustração e o título. Além disso, é importante colocar em discussão algumas questões que procuram antecipar as relações entre o título e os temas tratados no livro e dão ênfase aos termos felicidade e clandestina, promovendo a reflexão sobre como a felicidade pode ser clandestina.

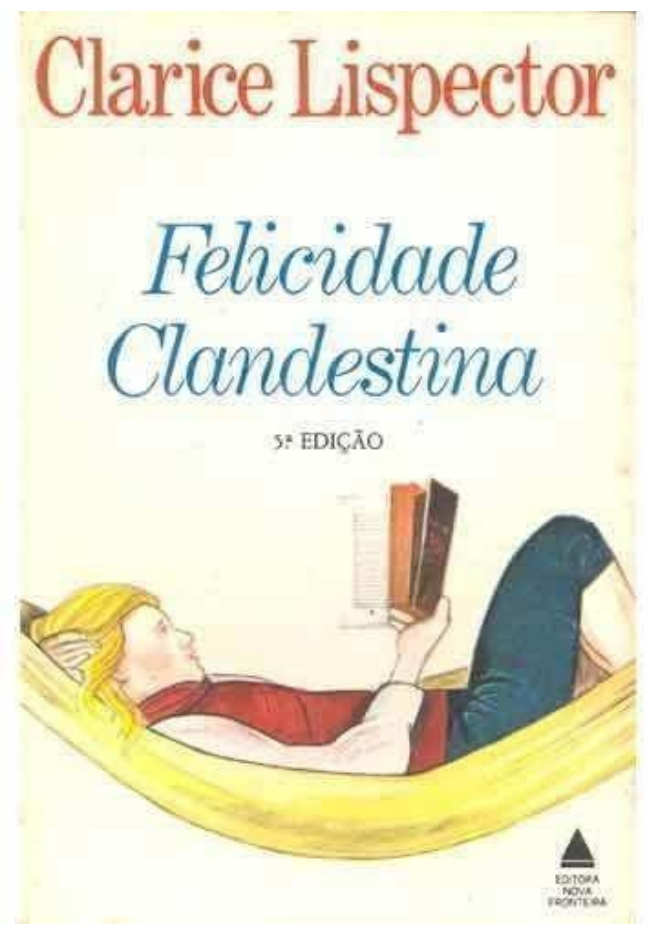

Essas relações têm por finalidade despertar o interesse do aluno pela leitura que se seguirá. Na capa apresentada, editada pele editora Nova Fronteira, na $5^{a}$ edição do livro de Clarice Lispector (1981), há uma personagem deitada numa rede, tendo os joelhos dobrados, uma mão posta atrás da cabeça e outra segurando um livro aberto. Ela é focalizada de perfil, 


\section{$=$ TRAMA $=$}

mostrando o rosto tranquilo e concentrado diante do livro. O nome da autora é apresentado na parte superior, em letras grandes vermelhas e o título vem abaixo em letras destacadas em itálico e azul, harmonizando com as vestimentas da personagem, que veste colete vermelho e calças curtas azuis.

Para trabalhar os aspectos tratados acima, sugerimos questões como as seguintes: a) Descreva a cena retratada na imagem da capa b) Qual parece ser o sentimento da pessoa retratada na imagem? c) Qual você imagina ser o assunto tratado no livro lido pela pessoa da imagem? d) O que significa a expressão 'clandestino(a)'? .f) A associação de 'felicidade' com 'clandestina' poderia soar estranho? A felicidade pode ser clandestina? g)Cite um exemplo em que a felicidade poderia ser clandestina no sentido de ilegal. h)Qual a possível relação entre o título do livro e a imagem da capa?

A próxima etapa é a leitura. Este é o momento de apresentar a materialidade do conto Felicidade Clandestina aos alunos. A leitura deve ser realizada em voz alta pelo professor, que vai fazendo pausas durante a leitura para discutir com a turma os conflitos e complicações do enredo, exigindo do aluno que se manifeste sobre quais são suas expectativas em relação ao desencadeamento das ações das personagens e dos possíveis desfechos. Após as pausas, sugerimos que o professor continue a leitura a fim de que os alunos possam verificar se suas expectativas se concretizaram. Na sequência, iniciamos a próxima etapa que é a da análise. Segundo CORSI (2015, p. 34):

Esta etapa se dá quando o leitor faz as primeiras compreensões da materialidade do enunciado narrativo, compondo sentidos para o que se encontra no interior da obra, traçando um caminho para chegar à interpretação. Assim, quando o leitor ultrapassar o sentido intrínseco do enunciado pode desvendar suas potencialidades interpretativas, fazendo inferências relacionadas aos conhecimentos de mundo que possui e reconstruindo ou ampliando o sentido da narrativa.

Para essa etapa, dividimos a análise em quatro partes, que procuram explorar os elementos que constituem os gêneros discursivos, amparados nos pressupostos teóricos do dialogismo de Bakhtin (1997). Para a divisão dessa análise em partes, levamos em consideração a proposta elaborada por Perfeito, Ohushi e Borges (2010, p. 55-56) que propõem observar no trabalho com os gêneros discursivos em sala de aula, aspectos concernentes:

\footnotetext{
ao contexto de produção - autor/enunciador [físico e social], destinatário/interlocutor [físico e social], finalidade, época e local de publicação e de circulação;

ao conteúdo temático - ideologicamente conformado - temas avaliativamente manifestados por meio dos gêneros, explorando-se, assim, sobretudo na leitura, para além da decodificação, a predição, inferência, críticas, criação de situaçõesproblema, emoções suscitadas etc.;

à construção, forma composicional - elementos de estrutura comunicativa e de significação e

às marcas linguístico-enunciativas - de regularidade na construção composicional e linguística do gênero, veiculadas dentre outras, pela expressividade do locutor.
}

Nesse sentido, a primeira parte é denominada de Entendendo o texto, na qual foram elaboradas questões que procuram promover a decodificação e inferências, bem como explorar aspectos da composição, capazes de conduzir o aluno à compreensão de elementos muito importantes da narrativa, como tempo, espaço, construção das personagens envolvidas no enredo, conflito gerador e o desfecho da história. Ao explorar esses aspectos, intencionamos 
levar o aluno a compreender como eles atendem ao projeto de dizer da autora. A seguir, algumas questões dessa etapa: a) Quais são os personagens? Têm nomes? b) Em que pessoa do discurso o conto foi escrito? O que essa escolha revela sobre os fatos narrados? c) Leia o trecho a seguir: "...até para aniversário, em vez de pelo menos um livrinho barato, ela nos entregava em mãos um cartão-postal da loja do pai. Ainda por cima era de paisagem do Recife mesmo, onde morávamos, com suas pontes mais do que vistas". O trecho acima deixa claro onde a história se passa? O que a narradora parece sentir em relação ao lugar onde a história se passa? Explique. d) No início do conto, como a narradora descreve a personalidade da colega de turma? Qual parece ser o seu sentimento em relação à colega? e) Ao longo da história, que acontecimento marca o início de uma relação mais próxima entre a narradora e a colega? f) De acordo com o texto, qual era sonho da narradora? O que esse sonho revela ao leitor sobre a sua personalidade? g) No texto, a colega de escola da narradora é descrita como alguém cruel. Quais atitudes da menina, a narradora considera cruéis? h) O que significa a expressão "tortura chinesa"? Faça uma pesquisa e explique o sentido da expressão. i) Por que a protagonista se submeteu a essa tortura? j) As duas personagens da crônica pertencem à mesma classe social? Comprove sua resposta com trechos do texto. I) O conto Felicidade Clandestina é construído em torno de alguns sentimentos da narradora: inveja, esperança e felicidade. Encontre no texto trechos que exemplifiquem esses três sentimentos. Use o quadro para organizar suas ideias.

\begin{tabular}{|l|l|}
\hline Inveja & \\
\hline Esperança & \\
\hline Felicidade & \\
\hline
\end{tabular}

m) Quem é a responsável por dar a narradora a felicidade que ela tanto buscava? n) Observe o trecho a seguir e responda: "E o pior para essa mulher não era a descoberta do que acontecia. Devia ser a descoberta horrorizada da filha que tinha. Ela nos espiava em silêncio: a potência de perversidade de sua filha desconhecida e a menina loura em pé à porta, exausta, ao vento das ruas de Recife." 1) O que se pode concluir que a mãe descobriu sobre a filha? Por que essa descoberta a deixou horrorizada? 2) O que a atitude da mãe logo após essa descoberta nos revela sobre o seu caráter? o) Que atitude a menina teve quando o livro enfim ficou em suas mãos?

A segunda parte da etapa da leitura procura explorar o contexto de produção da obra a fim de levar o aluno a compreender quem são os seus interlocutores, em que situação se encontram, qual o papel que ocupam na sociedade e em que época histórica o enunciado foi produzido. Para tanto, selecionamos a capa de uma edição diferente da que foi apresentada no momento da antecipação. As questões elaboradas para este momento instigam o leitor a buscar compreender os motivos que levam um livro a ser publicado mais de uma vez. O intuito dessa parte da oficina literária é promover a reflexão sobre a qualidade das obras de Clarisse Lispector, especialmente da obra Felicidade Clandestina que, apesar de ter sido publicada pela primeira vez em 1971, continua sendo apreciada por muitos leitores. A seguir, alguns exemplos de questões referentes ao contexto de produção: a) $O$ que se pode concluir depois de saber que o livro Felicidade Clandestina teve outras publicações? b) Além de livros, onde mais o 


\section{$=$ TRAMA $=$}

"Conto Felicidade Clandestina poderia ser publicado"? c) A data de publicação da obra é 1971. Pensando nisso, é possível dizer que o tema abordado no texto é antiquado ou ainda encontrase atual? Por quê?

A terceira parte desta etapa aborda algumas questões referentes ao conteúdo temático e procura explorar qual é a ideia de felicidade defendida no texto; como essa ideia é apresentada no texto, se de forma irônica, engraçada ou sentimental e o que o tratamento dado ao tema felicidade revela ao leitor sobre a autora e sobre o gênero conto.

Na quarta e última parte desta etapa de análise, criamos questões que exploram o estilo que, para Bakhtin (1997, p.283) pode "refletir a individualidade do falante (ou de quem escreve)." Esta parte procura explorar a riqueza das escolhas linguísticas realizadas por Clarice Lispector e como essas escolhas contribuem para a construção do conceito de felicidade no conto. Exploram também a funcionalidade de algumas classes gramaticas como os verbos na marcação do tempo da narrativa e na construção dos movimentos da protagonista, revelando muitas vezes o seu estado de espírito diante das idas e vindas em busca de seu objeto de desejo: o livro. As escolhas lexicais da autora e a ordem das ações oferecem ao aluno informações sobre a característica de captação da vivência interior das personagens criadas por Clarice, que resulta numa narrativa introspectiva. A seguir, algumas questões que abordam o estilo: a) Em que momento da vida da protagonista ocorrem os fatos narrados? Comprove sua resposta com um trecho do texto. b) Circule no trecho que você transcreveu as palavras responsáveis por deixar claro o tempo da narrativa. c) Em que momento de sua vida a protagonista nos conta sua história? Justifique sua resposta com elementos do conto. d)Observe o trecho a seguir em que a narradora descreve o seu objeto de desejo e responda as questões: "Era um livro grosso, meu Deus, era um livro para se ficar vivendo com ele, comendo-o, dormindo-o. E completamente acima de minhas posses. Disse-me que eu passasse pela sua casa no dia seguinte e que ela o emprestaria". 1) Sublinhe no trecho acima a parte que destaca a intensidade do desejo da narradora pelo livro. 2) Qual parte do trecho acima antecipa ao leitor a atitude de tortura assumida pela personagem filha do dono da livraria? 3) Quais palavras desse trecho reforçam a ideia de possiblidade e incerteza? e) No trecho: "Até o dia seguinte eu me transformei na própria esperança da alegria: eu não vivia, eu nadava devagar num mar suave, as ondas me levavam e me traziam". 1) Que palavras indicam ações que se repetiam? 2) Reescreva o trecho de forma a indicar que as ações aconteceram uma única vez. 3) Ao reescrever, houve alteração no sentimento da narradora? Qual foi o sentido produzido pela alteração? f) Quais são as razões atribuídas pela protagonista para a rivalidade existente entre as meninas e a garota ruiva? Como ela chega a essa conclusão? g) Há outras passagens do texto que confirmam isso? h) Em alguns momentos do conto, Clarice Lispector utiliza um recurso bastante recorrente em vários escritores da época. Trata-se da introspecção psicológica, por meio da qual "procura-se desvendar o universo mental da personagem de forma linear, com bastante nitidez de tempo e espaço. Nesse caso, o leitor tem pleno domínio da situação e distingue com facilidade momentos do passado, momentos do presente e momentos de imaginação" (LISPECTOR, 1981). Identifique em qual dos fragmentos abaixo ocorre esse processo.

( ) Mas que talento tinha para a crueldade. Ela toda era pura vingança, chupando balas com barulho. Como essa menina devia nos odiar, nós que éramos imperdoavelmente bonitinhas, esguias, altinhas, de cabelos livres. Comigo exerceu com calma ferocidade o seu sadismo.

( ) Ela não morava num sobrado como eu, e sim numa casa. Não me mandou entrar. Olhando bem para meus olhos, disse-me que havia emprestado o livro a outra menina, e que eu voltasse no dia seguinte para buscá-lo. 


\section{$=\mathrm{T} R A M A=$}

( ) Ela era gorda, baixa, sardenta e de cabelos excessivamente crespos, meio arruivados. Tinha um busto enorme, enquanto nós todas ainda éramos achatadas. Como se não bastasse, enchia os dois bolsos da blusa, por cima do busto, com balas. Mas possuía o que qualquer criança devoradora de histórias gostaria de ter: um pai dono de livraria. i) No final do texto, a que a narradora compara o livro? j) Por que essa comparação reforça a ideia de clandestinidade?

A última etapa dessa proposta para a abordagem do texto literário é a interpretação. Segundo Micheletti (2000, p.16), logo depois da análise, na qual o texto foi desmontado para se aprofundar no interior do discurso que ele estabelece, vem a fase da interpretação que se configura como uma "re-montagem e, tal como um desenho animado, as palavras vão-se juntando e formando o texto já com um novo sentido para o leitor." Ainda, conforme a autora, é nesse momento que o texto ganha vida para o leitor, pois este lançou mão de todo o seu conhecimento de mundo e o pôs em movimento.

Com essa finalidade de levar o aluno a remontar o sentido do texto escolhido para a elaboração dessa proposta, optamos por oferecer-Ihe a possibilidade de elaborar a sua própria ideia de felicidade por meio da produção de uma fanfiction. Fanfiction, conforme Azzarri e Custódio (2013), envolve escrita criativa, autoria e metalinguagem, circula nas nuvens, em sítios específicos e é um termo reduzido que significa "ficção de fã", faz parte da cultura pop e é construído de maneira essencialmente colaborativa. É um gênero que atende aos interesses do leitor da contemporaneidade, que, nas palavras de Candido (2018, p. 249), "[...] quer participar, quer ser autor também, quer enfrentar os perigos da escrita e não somente da leitura. Temos um público participativo, que exige para si a voz antes legada apenas aos escritores". Dessa forma, entendemos a produção de fanfiction como uma alternativa de interpretação e também de expansão do conto Felicidade Clandestina e elaboramos a seguinte proposta:

No conto Felicidade Clandestina, a narrativa é construída a partir do desejo de uma menina por um livro, que é o motivo de toda a sua felicidade. a) Se você pudesse reescrever essa história, que objeto seria o motivo da sua felicidade clandestina? b) Que elementos da história você modificaria? Para que o aluno planeje a sua produção, elaboramos um roteiro no formato de tabela, capaz de organizar a sua produção e levá-lo a se familiarizar com a construção composicional do gênero fanfiction. O roteiro contempla itens como: título, sinopse da história, personagens do conto Felicidade Clandestina que aparecerão em seu texto, personagens novas, descrição das personagens (características físicas e psicológicas) e lugar onde a história se passa, conforme quadro a seguir:

ROTEIRO DE PLANEJAMENTO PARA A PRODUÇÃO DA FANFIC

Título
Sinopse da história
Personagens do conto que aparecerão
Personagens novos
$\begin{aligned} & \text { Descrição dos personagens (características } \\ & \text { físicas e psicológicas) }\end{aligned}$

Lugar onde a história se passa

Revista Trama | Volume 16 | Número 39 | Ano 2020 | pp. 91-103 | e-ISSN 1981-4674 


\section{$=$ TRAMA $=$}

Após o planejamento, é o momento de produção. Sugerimos que esta etapa da oficina seja realizada no laboratório de informática da escola ou em outro ambiente com computadores. Depois da produção, faz-se necessário que o professor faça a leitura e a correção dos contos produzidos. Logo depois, é o momento de apresentar aos alunos as várias páginas de fanfictions existentes na internet. Para esta oficina, escolhemos a página Fanfics Brasil (https://fanfics.com.br/). É importante orientar os alunos no cadastramento na página, já que precisam estar cadastrados para poder publicar a sua fanfiction. Para isso, descrevemos a seguir um passo a passo para o cadastro no site fanfics brasil:

$1^{\circ}$ Passo: Acesse a Internet e busque pelo site www. https://fanfics.com.br/;

$2^{\circ}$ Passo: Acesse ao item "cadastro" e faça o seu cadastramento na página. Nesse momento você precisará preencher alguns dados importantes como: usuário, criar uma senha e informar um e-mail para receber as informações sobre o seu cadastramento;

$3^{\circ}$ Passo: Após preencher o cadastro, uma mensagem será enviada do site para o email informado por você. Ao acessar o seu e-mail você obterá o acesso ao site com facilidade;

$4^{\circ}$ Passo: Agora, basta você digitar o seu usuário e senha e poderá ter acesso a todas as informações do site.

$5^{\circ}$ Passo: Para criar a sua Fanfic, basta clicar no item "Criar Nova Fanfic" situado no lado esquerdo da tela, que abrirá uma janela para que você adicione a sua história. Preencha as informações solicitadas como, categoria e título. Se você quiser, pode até exportar alguma imagem que possa ilustrar a sua história. Agora, basta você digitar o seu usuário e senha e poderá ter acesso a todas as informações do site. Cole no campo Sinopse da Fanfic, a história criada por você e depois é só clicar em Criar Fanfic. Pronto, sua história poderá ser lida por todos que tem acesso à plataforma.

Durante a criação da fanfic, é importante ressaltar que o aluno poderá escolher imagens que ilustrem a sua história, enriquecendo a sua produção e conferindo-Ihe um caráter de exclusividade. Em seguida, é muito importante que os alunos acessem a página para ler as produções dos demais e possam interagir no ambiente virtual, por meio de comentários e likes.

Segundo Candido (2018, p.260), "Trabalhar com fanfics é uma maneira de letramento literário muito mais eficaz do que as velhas e antigas listas com definições sobre o que é um narrador, o que é o espaço, a personagem ou qualquer outro elemento da narrativa ou da poesia mesmo". Ainda segundo o mesmo autor, o trabalho com as fanfictions torna as produções dos alunos mais reais, já que dá a eles um público leitor efetivo, colocando o texto em circulação em ambientes reais. No caso da proposta aqui elaborada, a fanfiction dá voz aos ideais de felicidade clandestina que todos os indivíduos, principalmente o público ao qual esta proposta se destina, guardam secretamente dentro de si.

\section{CONSIDERAÇÕES FINAIS}

O trabalho com o texto literário em sala de aula ainda se apresenta como um dos grandes desafios do professor de Língua Portuguesa. Entretanto, propostas pedagógicas engajadas com o compromisso de formar leitores críticos, capazes de ultrapassar a superficialidade da materialidade textual, apresentam-se como subsídios muito importantes na constituição do trabalho do professor.

Nesse sentido, esperamos que essa proposta para abordagem do texto literário possa contribuir para o letramento literário dos alunos da fase final do Ensino Fundamental, uma vez que procura promover uma leitura aprofundada de um conto pertencente ao cânone literário e apresenta a possibilidade de refletir sobre um tema tão caro aos estudantes dessa fase de ensino na contemporaneidade. A proposta de produção sugerida procura ampliar a leitura do aluno por meio da produção de outro gênero discursivo, as fanfictions. Gênero esse que atende 
às expectativas dessa geração do século XXI, pois circula na esfera midiática, dominada por eles e os coloca numa posição de protagonistas de uma situação discursiva real.

\section{REFERÊNCIAS}

AZZARI, E. F.; CUSTÓDIO, M. A. Fanfics, Google Docs... A produção textual colaborativa. In: ROJO, R. (org.). Escol@ conectada. São Paulo: Parábola Editorial, 2013.

BAKHTIN, Mikhail Mikhailovich. Estética da criação verbal. Tradução de Maria Ermantina Galvão G. Pereira. São Paulo: Martins Fontes, 1997.

BRAIT, B; MELO R. Enunciado/enunciado concreto/ enunciação. In: BRAIT, B. (Org.). Bakhtin: conceitoschave. São Paulo: Contexto, 2005.

CÂNDIDO, A. O direito à literatura. In: CÂNDIDO, A. Vários escritos. Rio de Janeiro: Ouro Sobre Azul, 2004. p. $169-191$

CANDIDO, W.R. O papel da universidade na formação docente: Caminhos para o pensamento crítico em sala de aula. Os textos e as ideologias, mídias, redes sociais, a literatura e outras formas de arte. In FLECK, G. F.; CORSI, M. da S.; CANDIDO, W. R. (Orgs). A pesquisa em Literatura e leitura na formação docente experiências da pesquisa acadêmica à prática profissional no ensino. Volume 2. Campinas-SP: Mercado das Letras, 2018.

CEREJA, W. R.\& MAGALHÃES, T.C. Literatura Brasileira: ensino médio. São Paulo: Atual, 2005 CHARTIER, R. As revoluções da leitura no ocidente. In: ABREU, M. (Org.). Leitura, história e história da leitura. Campinas, SP: Mercado das Letras; São Paulo: Fapesp, 1999.

COMPAGNON, A. Literatura para quê? Belo Horizonte: UFMG, 2009.

CORSI, M. da S.. A narrativa literária francesa como suporte para o letramento do leitor - aprendiz de FLE. Maringá: Eduem, 2015.

COSSON, R. Letramento literário: teoria e prática. 1. ed., $3^{a}$ reimp. São Paulo: Contexto, 2009.

Fanfics Brasil: plataforma para a publicação e leitura de Fanfics. Página incial. Disponível em

$<$ https://fanfics.com.br/>. Acesso em: 12 de dez. de 2019.

JOUVE, V. Por que estudar literatura?Trad. Marcos Bagno e Marcos Marcionilo. São Paulo: Parábola, 2012.

LISPECTOR, Clarice. Felicidade Clandestina: contos. Rio de Janeiro: Nova Fronteira, 1981, p.07-10.

MICHELLETI, G. Leitura e construção do real: o lugar da poesia na ficção. São Paulo: Cortez, 2000. 2001 .

G. Concepções e práticas de leitura na escola: o lugar do texto literário. Itinerários, Araraquara, n. 17,

PERFEITO, A. M.; OHUSCHI, M.C. G.; BORGES, C.A.G. Bula de remédio: da teoria à prática de sala de aula. In: OSÓRIO, E.M. (Org.) Mikhail Bakhtin: cultura e vida. São Carlos: Pedro e João Editores, 2010. p. 51-74. ZILBERMAN, Regina. A literatura infantil na escola. 11. ed. São Paulo: Global, 2003. 